\title{
Article \\ Clinicopathologic Profile of Breast Cancer in Germline ATM and CHEK2 Mutation Carriers
}

\author{
Angela Toss ${ }^{1,2, *(\mathbb{D})}$, Elena Tenedini ${ }^{3} \mathbb{D}$, Claudia Piombino $^{1} \mathbb{D}$, Marta Venturelli ${ }^{1} \mathbb{D}$, Isabella Marchi ${ }^{1}$, \\ Elisa Gasparini ${ }^{4}$, Elena Barbieri ${ }^{1}$, Elisabetta Razzaboni ${ }^{5}$, Federica Domati 1,3 , Federica Caggia ${ }^{1,3}$, \\ Giovanni Grandi ${ }^{3,6} \mathbb{D}^{\mathbb{D}}$, Francesca Combi ${ }^{7,8} \mathbb{D}^{\mathbb{D}}$, Giovanni Tazzioli ${ }^{3,8}$, Massimo Dominici ${ }^{1,3}$, \\ Enrico Tagliafico $^{3,9,10}$ (D) and Laura Cortesi ${ }^{1}$ (D)
}

1 Department of Oncology and Hematology, Azienda Ospedaliero Universitaria di Modena, 41124 Modena, Italy; claudia.piombino@outlook.com (C.P.); martaventurelli@msn.com (M.V.); marchi.isabella@policlinico.mo.it (I.M.); barbieri.elena@aou.mo.it (E.B.); federica.domati@unimore.it (F.D.); federica.caggia@unimore.it (F.C.); massimo.dominici@unimore.it (M.D.); hbc@unimore.it (L.C.)

2 Department of Surgery, Medicine, Dentistry and Morphological Sciences with Transplant Surgery, Oncology and Regenerative Medicine Relevance, University of Modena and Reggio Emilia, 41124 Modena, Italy

3 Department of Medical and Surgical Sciences, University of Modena and Reggio Emilia, 41124 Modena, Italy; tenedini.elena@aou.mo.it (E.T.); giovanni.grandi@unimore.it (G.G.); giovanni.tazzioli@unimore.it (G.T.); enrico.tagliafico@unimore.it (E.T.)

4 Department of Oncology, Arcispedale S. Maria Nuova IRCCS, 42123 Reggio Emilia, Italy; gaspariniel@ausl.re.it

5 Hospital Psychology Service, Azienda Ospedaliero Universitaria di Modena, 41124 Modena, Italy; razzaboni.elisabetta@aou.mo.it

check for updates

Citation: Toss, A.; Tenedini, E.; Piombino, C.; Venturelli, M.; Marchi, I.; Gasparini, E.; Barbieri, E.;

Razzaboni, E.; Domati, F.; Caggia, F.; et al. Clinicopathologic Profile of Breast Cancer in Germline ATM and CHEK2 Mutation Carriers. Genes 2021, 12, 616. https://doi.org/ 10.3390/genes12050616

Academic Editor: Carmen Criscitiello

Received: 4 April 2021

Accepted: 20 April 2021

Published: 21 April 2021

Publisher's Note: MDPI stays neutral with regard to jurisdictional claims in published maps and institutional affiliations.

Copyright: (C) 2021 by the authors. Licensee MDPI, Basel, Switzerland. This article is an open access article distributed under the terms and conditions of the Creative Commons Attribution (CC BY) license (https:/ / creativecommons.org/licenses/by/ $4.0 /)$.
6 Obstetrics and Gynecology Unit, Department of Obstetrics, Gynecology and Pediatrics, Azienda Ospedaliero Universitaria di Modena, 41124 Modena, Italy

7 Department of Biomedical, Metabolic and Neural Sciences, International Doctorate School in Clinical and Experimental Medicine, University of Modena and Reggio Emilia, 41124 Modena, Italy; francesca.combi@unimore.it

8 Division of Breast Surgical Oncology, Department of Medical and Surgical, Maternal-Infantile and Adult Sciences, Azienda Ospedaliero Universitaria di Modena, 41124 Modena, Italy

9 Diagnostic Hematology and Clinical Genomics Unit, Department of Laboratory Medicine and Pathology, Azienda Ospedaliero Universitaria di Modena, 41124 Modena, Italy

10 Center for Genome Research, University of Modena and Reggio Emilia, 41124 Modena, Italy

* Correspondence: angela.toss@unimore.it

Abstract: The most common breast cancer (BC) susceptibility genes beyond BRCA1/2 are ATM and CHEK2. For the purpose of exploring the clinicopathologic characteristics of BC developed by ATM or CHEK2 mutation carriers, we reviewed the archive of our Family Cancer Clinic. Since 2018, 1185 multi-gene panel tests have been performed. Nineteen ATM and 17 CHEK2 mutation carriers affected by 46 different BCs were identified. A high rate of bilateral tumors was observed in ATM (26.3\%) and CHEK2 mutation carriers (41.2\%). While $64.3 \%$ of CHEK2 tumors were luminal A-like, $56.2 \%$ of ATM tumors were luminal B-like/HER2-negative. Moreover, 21.4\% of CHEK2-related invasive tumors showed a lobular histotype. About a quarter of all ATM-related BCs and a third of CHEK2 BCs were in situ carcinomas and more than half of $A T M$ and $C H E K 2$-related BCs were diagnosed at stage I-II. Finally, $63.2 \%$ of $A T M$ mutation carriers and $64.7 \%$ of $C H E K 2$ mutation carriers presented a positive BC family history. The biological and clinical characteristics of ATM and CHEK2-related tumors may help improve diagnosis, prognostication and targeted therapeutic approaches. Contralateral mastectomy should be considered and discussed with ATM and CHEK2 mutation carriers at the first diagnosis of BC.

Keywords: breast cancer; ATM; CHEK2; genetic testing; bilateral tumor; mastectomy 


\section{Introduction}

The recent introduction of multigene panel testing for mutations associated with breast and/or ovarian cancer has raised new challenges in the management of both individuals at increased cancer risk and cancer patients. In addition to the known high-penetrance $B R C A 1 / 2$ mutations, pathogenic variants in other high/moderate-penetrance genes can increase the risk of breast and/or ovarian cancer. Nevertheless, while providing risk assessment, their clinical utility in terms of primary and secondary prevention, prognostication and treatment modalities are still uncertain [1].

The most common non-BRCA pathogenic or likely pathogenic variants were found in $A T M$ and $C H E K 2$ genes [2]. In particular, the mutation frequency for $A T M$ is $0.78 \%$ and for CHEK2 $1.08 \%$ in unselected breast cancer patients, whereas the prevalence in unaffected women is $0.41 \%$ for ATM and $0.42 \%$ for CHEK2 [3]. Both ATM and CHEK2 are considered as moderate-penetrance genes and are involved in DNA-double strand break repair mechanisms [4]. In particular, the ATM protein kinase is a critical intermediary in a number of cellular responses to ionizing irradiation and possibly other stresses. In addition, its dysfunction results in abnormal checkpoint responses in multiple phases of the cell cycle [5]. After DNA damage, ATM and DNA-dependent (DNA-PK) protein kinase activate $\mathrm{CHK} 2$, which in turn phosphorylates a number of downstream substrates involved in various cellular processes, including cell cycle arrest, apoptosis, DNA repair and mitosis [6] (Figure 1).

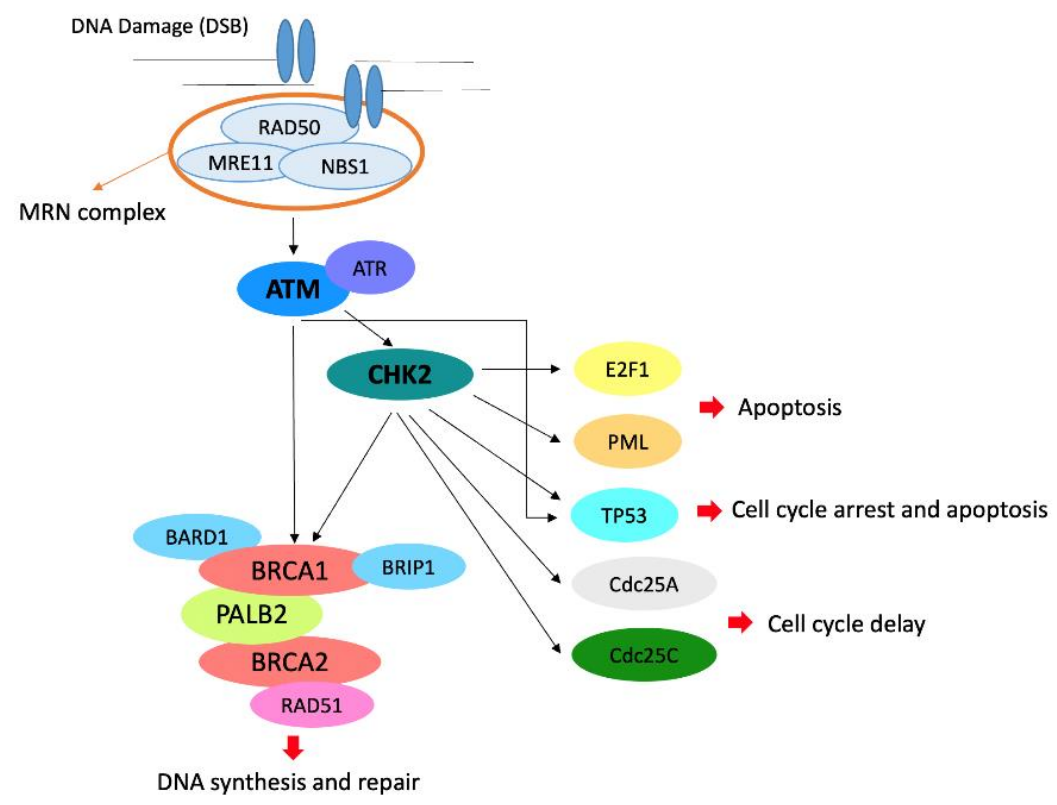

Figure 1. Role of ATM and CHK2 in the pathways of cell cycle arrest, apoptosis, DNA repair and mitosis. In particular, the MRN complex resects DNA at the double-strand break (DSB) and recruits ATM that phosphorylates CHK2 and recruits the BRCA complex.

Individuals carrying heterozygous pathogenic variants in ATM present a 33\% cumulative lifetime risk for $\mathrm{BC}$ by 80 years of age [7], whereas certain variants in the CHEK2 gene are associated with increased $\mathrm{BC}$ risk, with a cumulative lifetime risk ranging from $28 \%$ to $37 \%$ depending on family history [8,9]. Due to this increased risk, for both ATM and CHEK2 carriers, mammogram with consideration of breast MRI is recommended yearly from 40 years of age according to the current National Comprehensive Cancer Network (NCCN) guidelines [10]. Although only insufficient data are available, furthermore, bilateral risk-reducing mastectomy may be considered, based on family history [10]. Additionally, ATM heterozygous pathogenic variants have also been described in some cases of familial ovarian [11], pancreatic [12], and prostate cancer [13], whereas pathogenic CHEK2 variants were also associated to an increased risk of other malignancies including colon, 
prostate, kidney, bladder and thyroid cancers, according to specific mutations (frameshift or missense substitutions) [14].

So far, only a few small-sample studies investigated whether BC developed by ATM or CHEK2 mutation carriers includes distinct histopathological features and clinical outcomes from sporadic BC and BRCA1/2 associated tumors. Renault et al. [15] showed that most $A T M$-associated tumors are luminal B or luminal B/HER2+ tumors. Nizic-Kos et al. [16] reported that the majority of patients with CHEK2 pathogenic or likely pathogenic variants develop luminal A or luminal B BC subtypes. In a recent retrospective case-control study, finally, Bergstrom and colleagues [17] found that $B C$ patients with germline pathogenic variants of ATM, CHEK2, or PALB2 have an increased family history of breast cancer, tumor size $>2.0 \mathrm{~cm}$ at the time of diagnosis, and potentially an increased risk of recurrence compared to mutation-negative patients. However, lymph nodes, nuclear grade, histology, Ki-67 proliferation and receptor status were not different from sporadic tumors.

The aim of our study was to explore whether the presence of ATM or CHEK2 pathogenic or likely pathogenic germline variants in BC patients is associated with specific clinicopathologic characteristics and prognostic features at our institution.

\section{Materials and Methods}

\subsection{Study Population and Design}

The Modena Family Cancer Clinic (MFCC), located in the Emilia Romagna region (Northern Italy), offers genetic counseling to individuals with a personal or family history of $B C$ and/or ovarian cancer (OC) in accordance with regional criteria for $B R C A$ genetic testing [18]. Since the 8 January 2018, counseling has also been given to all patients affected by pancreatic cancer (PC) following Olaparib approval as a first-line maintenance treatment (Table 1). During pre-test counseling, family and personal histories of cancer are collected. At the same time, a family pedigree is drawn including third-degree relatives on both maternal and paternal sides. In particular, healthy women with BC and/or OC family history are referred to the MFCC by general practitioners or radiologists that perform population-based screening mammography. On the other hand, BC, OC and PC patients are referred to the MFCC by oncologists, radiologists, surgeons or gynecologists. Eligible individuals can undergo genetic testing. Then, in case of a positive result, the option of searching for specific pathogenic or likely pathogenic variant can be provided to other family members, in order to access risk-reducing surgery [19], chemoprevention studies [20] or more intensive surveillance programs [21,22]. After post-test counseling, finally, a copy of all patient documents and reports is stored in the MFCC archive.

Table 1. The MFCC criteria for genetic testing in BC, OC and PC cancer patients.

\begin{tabular}{l}
\hline BC and OC in the Same Patient or Family. \\
\hline OC, fallopian tube or primary peritoneal cancer (excluding mucinous and borderline) at any age. \\
\hline Male BC \\
\hline Triple negative BC diagnosed $\leq 60$ years. \\
\hline BC diagnosed $\leq 35$ years. \\
\hline PC at any age \\
\hline At least two first-degree blood relatives with BC with at least one diagnosed $\leq 40$ years or \\
bilateral in the same family. \\
\hline BC: breast cancer; OC: ovarian cancer; PC: pancreatic cancer.
\end{tabular}

Between 1998 and 2017, the MFCC offered BRCA1/2 genetic testing to BC and/or OC patients, first according to the Modena Criteria for genetic testing $[23,24]$ and subsequently, according to the criteria recommended by the Emilia Romagna region [18]. On the 8 January 2018, the Clinical Genomics Laboratory of the MFCC started to provide a Next Generation Sequencing (NGS) multigene panel testing to all new patients who met the Regional Criteria for $B R C A$ genetic testing and all PC patients. Furthermore, patients who 
tested negative for BRCA genes in the previous years were recalled to undergo the new multi-gene panel test. Clinical and pathologic characteristics of $B C$ patients testing positive for variants classified as pathogenic or likely pathogenic in the ATM or CHEK2 genes were then collected. These included age at first diagnosis, histotype, immunohistochemical profile of invasive carcinomas, clinical stage at diagnosis, type of breast and axillary surgery, radiotherapy, chemotherapy and rate of recurrence.

Estrogen Receptor (ER), Progesterone Receptor (PgR) and Human Epidermal growth factor Receptor 2 (HER2) expression were determined according to national pathology guidelines, which closely adhere to international standards $[25,26]$. According to the ESMO Clinical Practice Guidelines [27], for the purpose of prognostication and treatment decision making, tumors should be grouped into surrogate intrinsic subtypes, defined by routine histology and IHC data. In our study, in line with the 2013 St Gallen Consensus Conference [28] and local laboratory values, luminal A-like tumors have been defined as ER-positive, $\operatorname{PgR} \geq 20 \%$, HER2-negative and Ki67 $<20 \%$. On the other hand, luminal B-like tumors are characterized by ER-positive, and either Ki67 high ( $\geq 20 \%)$ or PgR low $(<20 \%)$ or HER2-positive.

All subjects gave their informed consent for inclusion before they participated in the study. The study was conducted in accordance with the Declaration of Helsinki, and the protocol was approved by the Ethics Committee of the Area Vasta Emilia Nord (Project identification code 125/2021/OSS* / AOUMO, Modena, Italy).

\subsection{Procedures for Multi-Gene Panel Testing}

Peripheral blood samples (PB) were collected into EDTA tubes, in accordance with the current revision of the Helsinki Declaration, and genomic DNA was extracted with the DNA Midi Kit via QIASymphony platform (Qiagen, Hilden, Germany); nucleic acid quantity/quality were checked by Qubit dsDNA High Sensitivity kit and Nanodrop (Thermo Scientific, Waltham, MA, USA).

Sequencing libraries were prepared using the CE-IVD SOPHiA HCS v1.1 kit, exclusively through the automated procedure implemented on the STARlet platform (Hamilton, https: / / www.hamiltoncompany.com/press-releases / application-note-automationof-the-hereditary-cancer-solution-hcs-by-sophia-genetics-on-a-starlet\#top, accessed on 20 April 2021). Individual library quantification was performed via fluorometric quantitation by Qubit dsDNA High Sensitivity kit (Thermo Scientific, Waltham, Massachusetts, USA) and quality control analysing the profile of each sample via capillary electrophoresis with Bioanalyzer DNA 1000 (Agilent Technologies, Santa Clara, CA, USA). Samples were run onto a 600-cycle format V3 flow-cell and sequenced via Illumina MiSeq DX platform according to their own and SOPHiA GENETICS' (Lausanne, Switzerland; Boston, MA, USA) protocols.

The SOPHiA HCS allows for the enrichment of coding and splicing regions of 26 genes (APC, ATM, BARD1, BRCA1, BRCA2, BRIP1, CDH1, CHEK2, EPCAM, FAM175A, MLH1, MRE11A, MSH2, MSH6, MUTYH, NBN, PALB2, PIK3CA, PMS2, PTEN, RAD50, RAD51C, RAD51D, STK11, TP53, XRCC2) and the pseudogene PMS2CL. This is known to be associated with increased risk for cancer syndromes. The sequencing data were simultaneously processed for single nucleotide variants (SNVs), indels and copy number variations (CNVs) using the SOPHiA DDM software (DDM) updated to the last available version at the time of sequencing. In accordance with local and international guidelines as well as with the patients' informed consent, data analysis and variant interpretation were limited to the following actionable gene set: APC, ATM, BARD1, BRCA1, BRCA2, BRIP1, CDH1, CHEK2, EPCAM, MLH1, MSH2, MSH6, MUTYH, NBN, PALB2, PMS2, PTEN, RAD50, RAD51C, RAD51D, STK11, TP53. Genetic variant annotations were also integrated with data from in literature and open source bioinformatics tools customized and validated in the laboratory (Annovar [29] and Variant Effect Predictor (VEP) [30]), and through consultation of specific databases: Leiden Open source Variation Database (https://grenada.lumc.nl/LOVD2/mendelian_genes/home.php? ac- 
cessed on 20 April 2021), ClinVar (http:/ /www.ncbi.nlm.nih.gov/clinvar/ accessed on 20 April 2021), 1000 Genomes Project (http:/ /www.1000genomes.org/data accessed on 20 April 2021), ExAC (http:/ / exac.broadinstitute.org/ accessed on 20 April 2021), dbSNP (http:/ / www.ncbi.nlm.nih.gov/projects/SNP/ accessed on 20 April 2021), The Genome Aggregation Database (http://gnomad.broadinstitute.org/ accessed on 20 April 2021), BRCA Share (http:/ / www.umd.be/BRCA1/ http:/ / www.umd.be/BRCA2/ accessed on 20 April 2021). Variants were reported using the international standard HGVS nomenclature and a classification into 5 classes (Pathogenic, Likely Pathogenic, Variant of Uncertain Significance, Likely Benign and Benign), according to the American College of Medical Genetics and Genomics (ACMG, Bethesda, MD, USA) criteria [31].

All gene variants or CNVs interpreted as Pathogenic or Likely Pathogenic were confirmed by Sanger sequencing performed with predesigned primers (the BigDye Direct Cycle Sequencing Kit), analyzed through the Applied Biosystems 3500xL Dx Genetic Analyzer platform and SeqScape3 software (Thermo Scientific), or by MLPA (MRC-Holland, Amsterdam, The Netherlands) and examined through the Coffalyser.Net software (MRCHolland) updated to the latest available version.

\section{Results}

\subsection{Overall Population}

Since the 8 January 2018, 1185 multi-gene panel tests have been performed. Of these tests, 1026 were performed on BC patients (422 of these on those who previously tested negative for BRCA genes). In addition, 24 were performed on BC and OC patients, with 11 of these previously testing negative for BRCA genes. Moreover, 76 tests were conducted on OC patients, 48 of these previously testing negative for BRCA genes, and 59 on PC patients (never tested before). Overall, ATM pathogenic or likely pathogenic germline variants were found in 16 index $\mathrm{BC}$ cases (detection rate among $\mathrm{BC}$ patients: $1.5 \%$ ) and in 3 relatives affected by BC (Figure 2). On the other hand, CHEK2 pathogenic or likely pathogenic germline variants were found in 16 index $\mathrm{BC}$ cases (detection rate among $\mathrm{BC}$ patients: $1.5 \%$ ) and one relative affected by BC (Figure 2). The likely pathogenic and pathogenic variants of ATM and CHEK2 detected in our population are listed in Table 2.

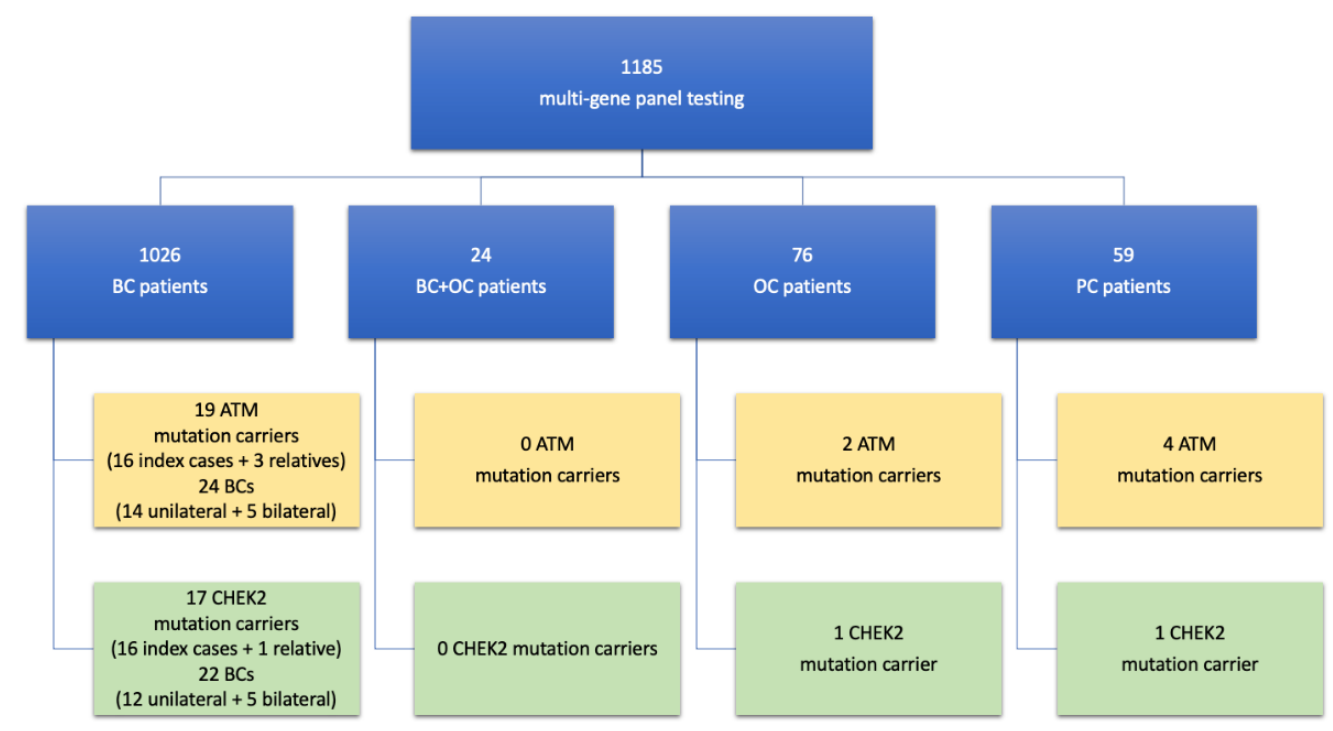

Figure 2. Study flow-chart. 
Table 2. Likely pathogenic and pathogenic variants of ATM and CHEK2 in our study population of BC patients.

\begin{tabular}{cccc}
\hline Variants of ATM Detected & Variant Classification & \multicolumn{2}{c}{ Number of BC Patients } \\
\hline c.6154G $>$ A, p.Glu2052Lys & Likely pathogenic & 5 index cases & 1 relative \\
c.2838+2162_4110-292del & Pathogenic & 1 index case & 1 relative \\
c.5441T>A,p.Leu1814* & Pathogenic & 1 index case & 1 relative \\
c.(8850+1_8851-1)_*3591_?)del, p.(?) & Pathogenic & 1 index case & - \\
c.8010+1delG & Likely pathogenic & 1 index case & - \\
c.5697C $>$ A, p.Cys1899* & Pathogenic & 1 index case & - \\
c.7327C $>$ T, p.Arg2443* & Pathogenic & 1 index case & - \\
c.2192dupA, p.Tyr731* & Pathogenic & 1 index case & - \\
c.2135C $>$ G, p.Ser712* & Likely pathogenic & 1 index case & - \\
c.8395_8404del10, p.Phe2799Lysfs *4 & Pathogenic & 1 index case & - \\
c.8814_8824del, p.Met2938Ilefs * & Pathogenic & 1 index case & - \\
c.5932G $>$ T, p.Glu1978* & Pathogenic & 1 index case & - \\
\hline Variants of CHEK2 detected & Variant classification & Number of BC patients \\
\hline c.190G $>$ A, p.Glu64Lys & Likely pathogenic & 5 index cases & - \\
c. $470 T>C$ C, p.Ile157Thr & Pathogenic & 3 index cases & - \\
c.1169A $>$ C, p.Tyr390Ser & Likely pathogenic & 2 index cases & 1 relative \\
c.1100delC, p.Thr367Metfs ${ }^{*} 15$ & Pathogenic & 2 index cases & - \\
c.1189A $>$ C, p.Tyr390Ser & Likely pathogenic & 1 index case & - \\
c.592+3A $>$ T, p.(?) & Likely pathogenic & 1 index case & - \\
c.549G $>$ C, p.Leu183Phe & Pathogenic & 1 index case & - \\
c.85C $>$ T, p.Gln29* & Pathogenic & 1 index case & - \\
\hline
\end{tabular}

The final analysis included $36 \mathrm{BC}$ patients (19 ATM mutation carriers and 17 CHEK2 mutation carriers) affected by 46 different BCs, with ten patients developing bilateral BC. The characteristics of patients, tumors and treatments are outlined in Table 3.

Table 3. Patient and tumor characteristics.

\begin{tabular}{ccc}
\hline & $\begin{array}{c}\text { BC in ATM Mutation } \\
\text { Carriers }(\boldsymbol{n = 2 4 )}\end{array}$ & $\begin{array}{c}\text { BC in CHEK2 Mutation } \\
\text { Carriers }(\boldsymbol{n}=\mathbf{2 2})\end{array}$ \\
\hline Median age at First BC Diagnosis, Years & 46.9 & 46.1 \\
\hline Hystotype (n, \%) & $(n=24)$ & $(n=22)$ \\
In situ ductal carcinoma & $6(25)$ & $6(30)$ \\
Invasive ductal carcinoma & $16(66.7)$ & $11(55)$ \\
Invasive lobular carcinoma & $2(8.3)$ & $3(15)$ \\
data not available & 0 & 2 \\
\hline Clinical Stage at diagnosis (n, \%) & $(n=24)$ & $(n=22)$ \\
is & $6(27.3)$ & $6(30)$ \\
I/II & $13(59.1)$ & $11(55)$ \\
III & $3(13.6)$ & $2(10)$ \\
IV & 0 & 2 \\
data not available & 2 & $(n=16)$ \\
Immunohistochemical profile & $(n=18)$ & $11(78.6)$ \\
of invasive carcinomas (n, \%) & $9(56.3)$ & $9(64.3)$ \\
HR+/HER2- & $4(25.1)$ & $2(14.3)$ \\
Luminal A-like & $5(31.2)$ & 0 \\
Luminal B-like & 0 & $3(21.4)$ \\
HR-/HER2+ & $4(25)$ & 0 \\
HR+/HER2+ & $3(18.8)$ & 2 \\
TNBC & 2 & \\
data not available & &
\end{tabular}


Table 3. Cont.

\begin{tabular}{|c|c|c|}
\hline & $\begin{array}{c}\text { BC in ATM Mutation } \\
\text { Carriers }(n=24)\end{array}$ & $\begin{array}{l}\text { BC in CHEK2 Mutation } \\
\text { Carriers }(n=22)\end{array}$ \\
\hline Grade of invasive carcinomas (n, \%) & $(n=18)$ & $(n=16)$ \\
\hline G1-2 & $6(42.8 \%)$ & $8(57.1 \%)$ \\
\hline $\mathrm{G} 3$ & $8(57.1 \%)$ & $6(42.8 \%)$ \\
\hline data not available & 4 & 2 \\
\hline Breast Surgery $(\mathrm{n}, \%)$ & $(n=24)$ & $(n=22)$ \\
\hline Mastectomy & $7(33.3)$ & $10(55.6)$ \\
\hline Conserving surgery & $13(61.9)$ & $8(44.4)$ \\
\hline No breast surgery & $1(4.8)$ & 0 \\
\hline data not available or stage IV & 3 & 4 \\
\hline Axillary Surgery (n, \%) & $(n=24)$ & $(n=22)$ \\
\hline Sentinel node biopsy & $11(52.4)$ & $7(38.9)$ \\
\hline Axillary node dissection & $4(19)$ & $7(38.9)$ \\
\hline No axillary surgery & $6(28.6)$ & $4(22.2)$ \\
\hline data not available or stage IV & 3 & 4 \\
\hline Radiotherapy (n, \%) & $(n=24)$ & $(n=22)$ \\
\hline Yes & $16(84.2)$ & $7(41.2)$ \\
\hline No & $3(15.8)$ & $10(58.8)$ \\
\hline data not available or stage IV & 5 & 5 \\
\hline $\begin{array}{l}\text { Neoadjuvant chemotherapy } \\
\text { in invasive carcinomas (n, \%) }\end{array}$ & $(n=18)$ & $(n=16)$ \\
\hline Yes & $6(42.9)$ & $1(9.1)$ \\
\hline No & $8(57.1)$ & $10(90.9)$ \\
\hline data not available or stage IV & 4 & 5 \\
\hline $\begin{array}{c}\text { Adjuvant chemotherapy } \\
\text { in invasive carcinomas (n, \%) }\end{array}$ & $(n=18)$ & $(n=16)$ \\
\hline Yes & $7(53.8)$ & $4(36,4)$ \\
\hline No & $6(46.2)$ & $7(63,6)$ \\
\hline data not available or stage IV & 5 & 5 \\
\hline $\begin{array}{l}\text { Local or distant recurrence in } \\
\text { localized BC at diagnosis (n, \%) }\end{array}$ & $(n=24)$ & $(n=20)$ \\
\hline Yes & $0(0)$ & $1(5)$ \\
\hline No & $24(100)$ & $19(95)$ \\
\hline $\begin{array}{l}\text { Median follow-up since diagnosis } \\
\text { (months) }\end{array}$ & 106 & 152 \\
\hline
\end{tabular}

Additionally, in 24 patients affected by both BC and OC, neither ATM nor CHEK2 likely pathogenic or pathogenic variants were detected. In 76 OC patients, two ATM (one index case and one relative) and one CHEK2 (index case) likely pathogenic or pathogenic variants were found. In 59 PC patients, finally, four ATM (all index cases) and one CHEK2 (index case) likely pathogenic or pathogenic variants were detected.

\subsection{ATM Mutation Carriers}

Median age at first $\mathrm{BC}$ diagnosis in ATM mutation carriers was 46.9 years. Five patients $(5 / 19,26.3 \%)$ developed bilateral BC (one of them synchronous). Therefore, 24 tumors were analyzed in ATM carriers. Overall, 6 (25\%) tumors were accounted for as ductal carcinoma in situ, while invasive ductal and lobular carcinoma amounted to $16(66.7 \%)$ and $2(8.3 \%)$, respectively. Invasive tumors were hormonal-receptor $(\mathrm{HR})$ positive and HER2 negative (HR+/HER2-) in $9(56.3 \%)$ cases, both HR and HER2 positive (HR+/HER2+) in 4 $(25 \%)$ cases and triple negative in $3(18.8 \%)$ cases. No HR-/HER2+ tumors were found. Thirteen (59.1\%) early-stage BC (I/II stage) and three (13.6\%) locally advanced tumors (III stage) were detected. No "de novo" metastatic BC were diagnosed. 
Based on available data, seven (33.3\%) tumors were treated by mastectomy and 13 $(61.9 \%)$ through breast conserving surgery. One patient underwent axillary node dissection without breast surgery for CUP syndrome. Eleven (52.4\%) sentinel node biopsies and four (19.1\%) axillary node dissections were performed (with no axillary surgery in 6 cases). In $16(84.2 \%)$ cases, radiation therapy followed breast surgery. Six out of $14(42.9 \%)$ patients diagnosed with invasive BC underwent neoadjuvant chemotherapy, whereas 7 out of 13 (53.8\%) patients underwent adjuvant chemotherapy. After a median follow up of 106 months, no local or distant recurrences were observed.

The most frequent mutation detected in the ATM gene was c.6154G>A, p.Glu2052Lys ( 5 out of 19 patients, $26.3 \%$ ). Three of these women developed bilateral BC and five out of eight of these tumors were categorized as DCIS.

Twelve patients $(63.2 \%)$ had a positive BC family history. In addition, a family history of ovarian, gastric, kidney/bladder and colon cancer were documented for 4 (21\%) patients each, while a family history of pancreatic cancer was reported for 3 (15.8\%) patients. One patient carrying an ATM pathogenic mutation with BC also developed gastric cancer. Moreover, two cases of epithelial ovarian cancer and four cases of pancreatic cancer were detected in six carriers of ATM pathogenic or likely pathogenic germline variants.

\subsection{CHEK2 Mutation Carriers}

Median age at first BC diagnosis in CHEK2 mutation carriers was 46.1 years. Five patients $(5 / 17,29.4 \%$ ) had bilateral BC (two of them synchronous). Therefore, 22 CHEK2associated tumors were analyzed. Overall, 6 (30\%) tumors were accounted for as ductal carcinoma in situ (Stage 0), while invasive ductal and lobular carcinoma amounted to 11 $(55 \%)$ and $3(15 \%)$, respectively. Invasive tumors were HR positive and HER2 negative (HR+/HER2-) in $11(78.6 \%)$ cases, both HR and HER2 positive (HR+/HER2+) in $3(21.4 \%)$ cases. No HR-/HER2+ and triple negative BCs were found. Eleven (55\%) early-stage BC (I/II stage), one (5\%) locally advanced tumor (III stage) and $2(10 \%)$ stage IV cancers were diagnosed.

In patients diagnosed with localized BC, 10 (55.6\%) tumors were treated by mastectomy and eight $(44.4 \%)$ by breast conserving surgery. Seven $(38.9 \%)$ sentinel node biopsies and seven $(38.9 \%)$ axillary node dissections were performed (with no axillary surgery in 4 cases). In seven $(41.2 \%)$ cases, radiation therapy followed breast surgery. One out of $11(9.1 \%)$ patients diagnosed with invasive BC underwent neoadjuvant chemotherapy, whereas 4 out of $11(36.4 \%)$ patients underwent adjuvant chemotherapy. After a median follow up of 152 months, only one local recurrence and no distant recurrences were observed in patients diagnosed with stage I-III BC.

The most frequent mutation detected in the CHEK2 gene was c.190G>A, p.Glu64Lys (5 out of 17 patients, $29.4 \%$ ). One of these women developed bilateral BC. The second most frequent pathogenic variant was c.470T $>$ C, p.Ile157Thr and one case of bilateral tumor was observed in these women. The founder mutation c.1100delC, p.Thr367Metfs*15 was present in two patients.

Eleven patients $(64.7 \%)$ had a positive BC family history and $6(35.3 \%)$ patients one of colon cancer, whereas $4(23.5 \%)$ patients had a prostate cancer family history and 4 $(23.5 \%)$ patients one of kidney/bladder cancer. Six of our BC patients carrying a CHEK2 pathogenic mutation were also diagnosed with thyroid carcinoma, acute myeloid leukemia, colon cancer, malignant melanoma, or uterine endometrial carcinoma. In addition to BC, the following malignancies were detected in five carriers of $C H E K 2$ pathogenic or likely pathogenic germline variants: pancreatic cancer, uterine cancer, prostate cancer, bladder cancer, multiple myeloma, kidney cancer, colon cancer, and thyroid carcinoma.

\section{Discussion}

The ATM and CHEK2 genes encode proteins that act as tumor suppressors and are involved in the DNA damage response following generation of DNA double-strand breaks (DSBs) [4]. Second to the BRCA1 and BRCA2 genes, the most common germline pathogenic 
or likely pathogenic variants predisposing to BC were found in the ATM and CHEK2 genes [2,3]. Individuals carrying heterozygous pathogenic variants in ATM or CHEK2 present a $33 \%$ and $28-37 \%$ cumulative lifetime risk for BC by 80 years of age, respectively [7-9]. Nevertheless, while the phenotypes of BRCA-related tumors have been widely characterized, little is known about the clinicopathologic features of ATM and CHEK2associated tumors, $\mathrm{BC}$ in the first place.

Interestingly, CHEK2 has the highest mutation prevalence in individuals of European descent, while the spectrum and frequency of pathogenic variants vary among specific European populations. In particular, the frequency of the founder mutation c.1100delC declines from the north to the south of Europe, whereas the most frequent European CHEK2 variant, p.I157T, has a carrier frequency of around $5 \%$ in Poles, Latvians, Hungarians and Russians and around 2-3\% in Czechs, Slovaks and Germans [32]. In our study, the most frequent CHEK2 mutation beyond c.470T>C, p.Ile157Thr (p.I157T), was c.190G>A, p.Glu64Lys. This likely pathogenic variant was observed at an allele frequency of $0.03 \%$ $(38 / 126,668)$ in individuals of European ancestry in large population cohorts [33] and has been associated with a personal and/or family history of breast, prostate, ovarian, colorectal, thyroid and pancreatic cancer [34-41]. On the other hand, the most frequent ATM mutation in our population was c.6154G>A, p.Glu2052Lys. This likely pathogenic variant has also previously been reported in individuals with a personal and/or family history of breast and/or ovarian cancer [34,42]. It is noteworthy that one of the ATM mutations described in our population, c.2838+2162_4110-292del, has been recently characterized at a molecular level by our research group [43].

Overall, our study identified 19 ATM mutation carriers with 24 breast tumors and 17 CHEK2 mutation carriers with 22 breast tumors. Median age at first BC onset was 46.9 years for $A T M$ and 46.1 years for CHEK2, in keeping with the literature [44]. Moreover, a high rate of bilateral tumors was observed in ATM (26.3\%) and CHEK2 mutation carriers (41.2\%). Previous studies differ from one another on the role of $A T M$ mutations in increasing the risk of contralateral BC [45-47]. On the other hand, bilateral BC was reported for 3.7-12.1\% of the patients harboring a CHEK2 likely pathogenic or pathogenic variant [48,49], whereas a recent analysis has provided evidence of contralateral BC in 19.5\% of Slovenian BC patients with CHEK2 mutations [16]. Moreover, a systematic review and meta-analysis by Akdeniz et al. [50] has recently shown a strong association with contralateral BC for carriers of CHEK2 c.1100delC mutation (relative risk, 2.7). In our study, however, only two patients with this variant were included (one of them with synchronous bilateral $\mathrm{BC})$, so that no conclusion can be drawn. Interestingly, the low frequency of the founder mutation c.1100delC variant in our cohort of patients is consistent with a previous analysis reporting this variant in only 1 of $939(0.11 \%, 95 \% \mathrm{CI}=0.00-0.59 \%)$ unrelated patients from Italian breast cancer families. These results indicate that the CHEK2 c.1100delC variant has marginal relevance to breast cancer predisposition in the Italian population [51]. In our cohort, interestingly, all patients underwent genetic testing after breast surgery: this could have determined the high rate of contralateral BC since none of these women underwent risk-reducing contralateral mastectomy. Although the evidence on whether contralateral prophylactic mastectomy improves survival for $B R C A$ carriers with $\mathrm{BC}$ is conflicting, this procedure reduces the risk of contralateral tumor by 93\% [52]. As a result, several international guidelines include this option $[10,53]$. However, no studies have investigated risk reduction and survival advantage in relation to contralateral prophylactic mastectomy for patients with a diagnosis of $\mathrm{BC}$ harboring ATM or CHEK2 likely pathogenic or pathogenic variants. In this regard, therefore, the decision should be shared with patients following a multidisciplinary and personalized approach.

In line with previous research [15,16,54-57] and unlike BRCA1 and PALB2-associated $\mathrm{BC}$ s that commonly present triple-negative subtype [58,59], ATM and CHEK2-related BC in our population mostly resulted in luminal-like subtypes. In particular, $64.3 \%$ of the $C H E K 2$ tumors were luminal A-like, whereas most of the ATM tumors were luminal B-like/HER2negative $(56.2 \%)$. Interestingly, $81.2 \%$ of the ATM tumors and $100 \%$ of the CHEK2 tumors 
were HR positive. In addition, $25 \%$ of $A T M$ BCs and $21.4 \%$ of $C H E K 2$ BCs were observed to be HER2 positive, while only $18.8 \%$ of the ATM BCs and none of the the CHEK2 tumors were accounted for as triple negative BC. Consistent with that, no CHEK2 mutation carriers were observed in a previous analysis of 1824 triple negative breast cancer patients [60]. Contrary to what was described in previous experiences [61,62], it is notable that most of the CHEK2 tumors (57.1\%) were associated with lower grades (G1-G2). Finally, 21.4\% of the CHEK2-related invasive tumors showed a lobular histotype, a high rate as previously highlighted in the literature $[16,63,64]$. In our population, however, due to the small sample size, the lobular histotype was not associated with any particular variant. On the other hand, ATM invasive BC in our population showed no particular histological subtype (88.9\% were invasive ductal carcinomas and $11.1 \%$ were invasive lobular carcinomas), as already observed elsewhere [15].

About a quarter of all ATM-related BCs and a third of CHEK2 BCs were in situ carcinomas and more than half of $A T M$ and $C H E K 2$-related BCs were diagnosed at stage I-II (59.1\% and 55\%, respectively), whereas $13.6 \%$ of the ATM BCs and $15 \%$ of the CHEK2 BCs were stage III-IV. Despite the early stages at diagnosis, 55.6\% of the CHEK2 BCs were treated by mastectomy and $38.9 \%$ by axillary node dissection, since most of these patients underwent surgery in the late 90 s when breast surgery was less conservative. A higher rate of $A T M$-associated BCs was treated with neoadjuvant chemotherapy $(42.9 \%)$ and/or adjuvant chemotherapy (53.8\%) compared to CHEK2 tumors (9.1\% and $36.4 \%$, respectively), reflecting the higher percentage of stage III, HER2 positive and triple-negative BC in ATMrelated tumors. Confirming good prognosis for luminal-like subtypes and early-stage BCs [65], after more than 8 years of follow up in both groups, only one local recurrence was observed in localized BCs at diagnosis.

As previously described for other cohorts [16,17], 63.2\% of ATM mutation carriers and $64.7 \%$ of CHEK2 mutation carriers presented a positive BC family history. Nevertheless, both germline ATM and CHEK2 likely pathogenic or pathogenic variants have been linked with susceptibility to several malignancies other than BC. In our population, accordingly, ATM families exhibited ovarian cancer in $21 \%$ of cases and pancreatic cancer in $15.8 \%$ of cases, besides gastric, kidney/bladder and colon tumors. On the other hand, CHEK2 families presented a recurrence of colon cancer (35.3\% of cases), prostate tumors $(23.5 \%)$ and kidney/bladder cancers (23.5\%).

As has already been the case with BRCA-associated tumors, the definition of biological and clinical characteristics of ATM and CHEK2-related tumors may help improve diagnosis, prognostication and targeted therapeutic approaches [66-68]. In particular, in light of the high rate of contralateral tumors described in our experience, we believe that contralateral mastectomy should be considered and discussed with ATM and even more with CHEK2 mutation carriers at the first diagnosis of BC. Further studies with larger patient cohorts are needed to confirm our findings and assist both patients and physicians in decision making and management recommendations in this subset of patients.

Author Contributions: Conceptualization, A.T. and L.C.; methodology, C.P.; validation, E.B. and E.R.; formal analysis, F.D.; investigation, E.G. and F.C. (Francesca Combi); resources, M.V.; data curation, E.T. (Elena Tenedini) and I.M.; writing-original draft preparation, C.P. and A.T.; writing-review and editing, E.T. (Elena Tenedini) and L.C.; visualization, G.G. and M.V.; supervision, G.T., M.D. and E.T. (Enrico Tagliafico); project administration, F.C. (Federica Caggia). All authors have read and agreed to the published version of the manuscript.

Funding: The APC was funded by the grant Ricerca Finalizzata Giovane Ricercatore 2018 with the project GR-2018-12367239.

Institutional Review Board Statement: The study was conducted in accordance with the Declaration of Helsinki, and the protocol was approved by the Ethics Committee of the Area Vasta Emilia Nord (Project identification code 125/2021/OSS* AOUMO).

Informed Consent Statement: Written informed consent was obtained from the patients to publish this paper. 
Data Availability Statement: The data presented in this study are available within the article.

Acknowledgments: The authors would like to thank the Angela Serra Association for Cancer Research for their support to patients and research activities.

Conflicts of Interest: The authors declare no conflict of interest associated with this manuscript.

\section{References}

1. Desmond, A.; Kurian, A.W.; Gabree, M.; Mills, M.A.; Anderson, M.J.; Kobayashi, Y.; Horick, N.; Yang, S.; Shannon, K.M.; Tung, N.; et al. Clinical actionability of multigene panel testing for hereditary breast and ovarian cancer risk assessment. JAMA Oncol. 2015, 1, 943-951. [CrossRef]

2. Kapoor, N.S.; Curcio, L.D.; Blakemore, C.A.; Bremner, A.K.; McFarland, R.E.; West, J.G.; Banks, K.C. Multigene panel testing detects equal rates of pathogenic BRCA1/2 mutations and has a higher diagnostic yield compared to limited BRCA1/2 analysis alone in patients at risk for hereditary breast cancer. Ann. Surg. Oncol. 2015, 22, 3282-3288. [CrossRef] [PubMed]

3. Hu, C.; Hart, S.N.; Gnanaolivu, R.; Huang, H.; Lee, K.Y.; Na, J.; Gao, C.; Lilyquist, J.; Yadav, S.; Boddicker, N.J.; et al. A Population-Based Study of Genes Previously Implicated in Breast Cancer. N. Engl. J. Med. 2021, 384, 440-451. [CrossRef] [PubMed]

4. Sun, Y.; McCorvie, T.J.; Yates, L.A.; Zhang, X. Structural basis of homologous recombination. Cell. Mol. Life Sci. 2020, 77, 3-18.

5. Pandita, T.K.; Lieberman, H.B.; Lim, D.S.; Dhar, S.; Zheng, W.; Taya, Y.; Kastan, M.B. Ionizing radiation activates the ATM kinase throughout the cell cycle. Oncogene 2000, 19, 1386-1391. [CrossRef] [PubMed]

6. Pommier, Y.; Weinstein, J.N.; Aladjem, M.I.; Kohn, K.W. Chk2 molecular interaction map and rationale for Chk2 inhibitors. Clin. Cancer Res. 2006, 12, 2657-2661. [CrossRef] [PubMed]

7. Marabelli, M.; Cheng, S.-C.; Parmigiani, G. Penetrance of ATM Gene mutations in breast cancer: A meta-analysis of different measures of risk. Genet. Epidemiol. 2016, 40, 425-431. [CrossRef] [PubMed]

8. Cybulski, C.; Wokołorczyk, D.; Jakubowska, A.; Huzarski, T.; Byrski, T.; Gronwald, J.; Masojć, B.; Deebniak, T.; Górski, B.; Blecharz, P.; et al. Risk of breast cancer in women with a CHEK2 mutation with and without a family history of breast cancer. $J$. Clin. Oncol. 2011, 29, 3747-3752. [CrossRef]

9. Piombino, C.; Cortesi, L.; Lambertini, M.; Punie, K.; Grandi, G.; Toss, A. Secondary Prevention in Hereditary Breast and/or Ovarian Cancer Syndromes Other Than BRCA. J. Oncol. 2020, 2020, 6384190:1-6384190:10. [CrossRef]

10. National Comprehensive Cancer Network. Genetic/Familial High-Risk Assessment: Breast, Ovarian, and Pancreatic (Version 2.2021). Available online: https:/ / www.nccn.org/professionals/physician_gls/pdf/genetics_bop.pdf (accessed on 17 December 2020).

11. Lu, H.-M.; Li, S.; Black, M.H.; Lee, S.; Hoiness, R.; Wu, S.; Mu, W.; Huether, R.; Chen, J.; Sridhar, S.; et al. Association of breast and ovarian cancers with predisposition genes identified by large-scale sequencing. JAMA Oncol. 2019, 5, 51-57. [CrossRef] [PubMed]

12. Shindo, K.; Yu, J.; Suenaga, M.; Fesharakizadeh, S.; Cho, C.; Macgregor-Das, A.; Siddiqui, A.; Witmer, P.D.; Tamura, K.; Song, T.J.; et al. Deleterious germline mutations in patients with apparently sporadic pancreatic adenocarcinoma. J. Clin. Oncol. 2017, 35, 3382-3390. [CrossRef]

13. Pilié, P.G.; Johnson, A.M.; Hanson, K.L.; Dayno, M.E.; Kapron, A.L.; Stoffel, E.M.; Cooney, K.A. Germline genetic variants in men with prostate cancer and one or more additional cancers. Cancer 2017, 123, 3925-3932. [CrossRef]

14. Cybulski, C.; Górski, B.; Huzarski, T.; Masojć, B.; Mierzejewski, M.; Debniak, T.; Teodorczyk, U.; Byrski, T.; Gronwald, J.; Matyjasik, J.; et al. CHEK2 is a multiorgan cancer susceptibility gene. Am. J. Hum. Genet. 2004, 75, 1131-1135. [CrossRef]

15. Renault, A.-L.; Mebirouk, N.; Fuhrmann, L.; Bataillon, G.; Cavaciuti, E.; Le Gal, D.; Girard, E.; Popova, T.; La Rosa, P.; Beauvallet, J.; et al. Morphology and genomic hallmarks of breast tumours developed by ATM deleterious variant carriers. Breast Cancer Res. 2018, 20, 28. [CrossRef]

16. Nizic-Kos, T.; Krajc, M.; Blatnik, A.; Stegel, V.; Skerl, P.; Novakovic, S.; Gazic, B.; Besic, N. Bilateral Disease Common Among Slovenian CHEK2-Positive Breast Cancer Patients. Ann. Surg. Oncol. 2020, 1-10. [CrossRef] [PubMed]

17. Bergstrom, C.; Pence, C.; Berg, J.; Partain, N.; Sadeghi, N.; Mauer, C.; Pirzadeh-Miller, S.; Gao, A.; Li, H.; Unni, N.; et al. Clinicopathological Features and Outcomes in Individuals with Breast Cancer and ATM, CHEK2, or PALB2 Mutations. Ann. Surg. Oncol. 2020. [CrossRef] [PubMed]

18. Giunta Della Regione Emilia Romagna. Rischio Eredo-Familiare Per Il Carcinoma Della Mammella-Approvazione Linee Guida Per Le Aziende Sanitarie Della Regione Emilia Romagna. Available online: https:/ / salute.regione.emilia-romagna.it/normativae-documentazione/leggi/regionali/delibere/dgr.-220-2011 (accessed on 17 December 2020).

19. Cortesi, L.; Razzaboni, E.; Toss, A.; De Matteis, E.; Marchi, I.; Medici, V.; Tazzioli, G.; Andreotti, A.; De Santis, G.; Pignatti, M.; et al. A rapid genetic counselling and testing in newly diagnosed breast cancer is associated with high rate of risk-reducing mastectomy in BRCA1/2-positive Italian women. Ann. Oncol. 2014, 25, 57-63. [CrossRef] [PubMed]

20. Razzaboni, E.; Toss, A.; Cortesi, L.; Marchi, I.; Sebastiani, F.; De Matteis, E.; Federico, M. Acceptability and adherence in a chemoprevention trial among women at increased risk for breast cancer attending the Modena Familial Breast and Ovarian Cancer Center (Italy). Breast J. 2013, 19, 10-21. [CrossRef] [PubMed] 
21. Cortesi, L.; Canossi, B.; Battista, R.; Pecchi, A.; Drago, A.; Dal Molin, C.; Toss, A.; De Matteis, E.; Marchi, I.; Torricelli, P.; et al. Breast ultrasonography (BU) in the screening protocol for women at hereditary-familial risk of breast cancer: Has the time come to rethink the role of BU according to different risk categories? Int. J. Cancer 2019, 144, 1001-1009. [CrossRef] [PubMed]

22. Cortesi, L.; De Matteis, E.; Toss, A.; Marchi, I.; Medici, V.; Contu, G.; Xholli, A.; Grandi, G.; Cagnacci, A.; Federico, M. Evaluation of Transvaginal Ultrasound plus CA-125 Measurement and Prophylactic Salpingo-Oophorectomy in Women at Different Risk Levels of Ovarian Cancer: The Modena Study Group Cohort Study. Oncology 2017, 93, 377-386. [CrossRef]

23. Federico, M.; Maiorana, A.; Mangone, L.; Turchetti, D.; Canossi, B.; Romagnoli, R.; Silingardi, V. Identification of families with hereditary breast and ovarian cancer for clinical and mammographic surveillance: The Modena Study Group proposal. Breast Cancer Res. Treat. 1999, 55, 213-221. [CrossRef] [PubMed]

24. Cortesi, L.; Turchetti, D.; Marchi, I.; Fracca, A.; Canossi, B.; Rachele, B.; Silvia, R.; Rita, P.A.; Pietro, T.; Massimo, F. Breast cancer screening in women at increased risk according to different family histories: An update of the Modena Study Group experience. BMC Cancer 2006, 6, 210. [CrossRef] [PubMed]

25. Wolff, A.C.; Hammond, M.E.H.; Allison, K.H.; Harvey, B.E.; Mangu, P.B.; Bartlett, J.M.S.; Bilous, M.; Ellis, I.O.; Fitzgibbons, P.; Hanna, W.; et al. Human Epidermal Growth Factor Receptor 2 Testing in Breast Cancer: American Society of Clinical Oncology/College of American Pathologists Clinical Practice Guideline Focused Update. J. Clin. Oncol. 2018, 36, $2105-2122$. [CrossRef] [PubMed]

26. Hammond, M.E.; Hayes, D.F.; Dowsett, M.; Allred, D.C.; Hagerty, K.L.; Badve, S.; Fitzgibbons, P.L.; Francis, G.; Goldstein, N.S.; Hayes, M.; et al. American Society of Clinical Oncology/College of American Pathologists guideline recommendations for immunohistochemical testing of estrogen and progesterone receptors in breast cancer. Arch. Pathol. Lab. Med. 2010, 134, 907-922. [CrossRef]

27. Cardoso, F.; Kyriakides, S.; Ohno, S.; Penault-Llorca, F.; Poortmans, P.; Rubio, I.T.; Zackrisson, S.; Senkus, E. ESMO Guidelines Committee. Early breast cancer: ESMO Clinical Practice Guidelines for diagnosis, treatment and follow-upt. Ann. Oncol. 2019, 30, 1194-1220. [CrossRef] [PubMed]

28. Goldhirsch, A.; Winer, E.P.; Coates, A.S.; Gelber, R.D.; Piccart-Gebhart, M.; Thürlimann, B.; Senn, H.J.; Wood, W.C. Personalizing the treatment of women with early breast cancer: Highlights of the St Gallen International Expert Consensus on the Primary Therapy of Early Breast Cancer 2013. Ann. Oncol. 2013, 24, 2206-2223. [CrossRef] [PubMed]

29. Wang, K.; Li, M.; Hakonarson, H. Annovar: Functional annotation of genetic variants from high-throughput sequencing data. Nucleic Acids Res. 2010, 38, e164. [CrossRef] [PubMed]

30. McLaren, W.; Gil, L.; Hunt, S.E.; Riat, H.S.; Ritchie, G.R.; Thormann, A.; Flicek, P.; Cunningham, F. The ensembl variant effect predictor. Genome Biol. 2016, 17, 122. [CrossRef]

31. Richards, S.; Aziz, N.; Bale, S.; Bick, D.; Das, S.; Gastier-Foster, J.; Grody, W.W.; Hegde, M.; Lyon, E.; Spector, E.; et al. Standards and guidelines for the interpretation of sequence variants: A joint consensus recommendation of the American College of Medical Genetics and Genomics and the Association for Molecular Pathology. Genet. Med. 2015, 17, 405-424. [CrossRef]

32. Stolarova, L.; Kleiblova, P.; Janatova, M.; Soukupova, J.; Zemankova, P.; Macurek, L.; Kleibl, Z. CHEK2 Germline Variants in Cancer Predisposition: Stalemate Rather than Checkmate. Cells 2020, 9, 2675. [CrossRef]

33. Lek, M.; Karczewski, K.J.; Minikel, E.V.; Samocha, K.E.; Banks, E.; Fennell, T.; O’Donnell-Luria, A.H.; Ware, J.S.; Hill, A.J.; Cummings, B.B.; et al. Analysis of protein-coding genetic variation in 60,706 humans. Nature 2016, 536, 285-291. [CrossRef]

34. Kraus, C.; Hoyer, J.; Vasileiou, G.; Wunderle, M.; Lux, M.P.; Fasching, P.A.; Krumbiegel, M.; Uebe, S.; Reuter, M.; Beckmann, M.W.; et al. Gene panel sequencing in familial breast/ovarian cancer patients identifies multiple novel mutations also in genes others than BRCA1/2. Int. J. Cancer 2017, 140, 95-102. [CrossRef]

35. Desrichard, A.; Bidet, Y.; Uhrhammer, N.; Bignon, Y.J. CHEK2 contribution to hereditary breast cancer in non-BRCA families. Breast Cancer Res. 2011, 13, R119. [CrossRef] [PubMed]

36. Eliade, M.; Skrzypski, J.; Baurand, A.; Jacquot, C.; Bertolone, G.; Loustalot, C.; Coutant, C.; Guy, F.; Fumoleau, P.; Duffourd, Y.; et al. The transfer of multigene panel testing for hereditary breast and ovarian cancer to healthcare: What are the implications for the management of patients and families? Oncotarget 2017, 8, 1957-1971. [CrossRef]

37. Gonzalez-Garay, M.L.; McGuire, A.L.; Pereira, S.; Caskey, C.T. Personalized genomic disease risk of volunteers. Proc. Natl. Acad. Sci. USA 2013, 110, 16957-16962. [CrossRef] [PubMed]

38. Dong, X.; Wang, L.; Taniguchi, K.; Wang, X.; Cunningham, J.M.; McDonnell, S.K.; Qian, C.; Marks, A.F.; Slager, S.L.; Peterson, B.J.; et al. Mutations in CHEK2 associated with prostate cancer risk. Am. J. Hum. Genet. 2003, 72, 270-280. [CrossRef] [PubMed]

39. Susswein, L.R.; Marshall, M.L.; Nusbaum, R.; Vogel Postula, K.J.; Weissman, S.M.; Yackowski, L.; Vaccari, E.M.; Bissonnette, J.; Booker, J.K. Pathogenic and likely pathogenic variant prevalence among the first 10,000 patients referred for next-generation cancer panel testing. Genet. Med. 2016, 18, 823-832. [CrossRef]

40. Yurgelun, M.B.; Kulke, M.H.; Fuchs, C.S.; Allen, B.A.; Uno, H.; Hornick, J.L.; Ukaegbu, C.I.; Brais, L.K.; McNamara, P.G.; Mayer, R.J.; et al. Cancer Susceptibility Gene Mutations in Individuals with Colorectal Cancer. J. Clin. Oncol. 2017, 35, $1086-1095$. [CrossRef]

41. Shirts, B.H.; Casadei, S.; Jacobson, A.L.; Lee, M.K.; Gulsuner, S.; Bennett, R.L.; Miller, M.; Hall, S.A.; Hampel, H.; Hisama, F.M.; et al. Improving performance of multigene panels for genomic analysis of cancer predisposition. Genet. Med. 2016, 18, 974-981. [CrossRef] 
42. Singh, J.; Thota, N.; Singh, S.; Padhi, S.; Mohan, P.; Deshwal, S.; Sur, S.; Ghosh, M.; Agarwal, A.; Sarin, R.; et al. Screening of over 1000 Indian patients with breast and/or ovarian cancer with a multi-gene panel: Prevalence of BRCA1/2 and non-BRCA mutations. Breast Cancer Res. Treat. 2018, 170, 189-196. [CrossRef] [PubMed]

43. Parenti, S.; Rabacchi, C.; Marino, M.; Tenedini, E.; Artuso, L.; Castellano, S.; Carretta, C.; Mallia, S.; Cortesi, L.; Toss, A.; et al. Characterization of New ATM Deletion Associated with Hereditary Breast Cancer. Genes 2021, 12, 136. [CrossRef]

44. Skasko, E.; Kluska, A.; Niwińska, A.; Kwiatkowska, E.; Bałabas, A.; Piatkowska, M.; Dabrowska, M.; Nowakowska, D.; Pieńkowski, T. Age at onset of bilateral breast cancer, the presence of hereditary BRCA1, BRCA2, CHEK2 gene mutations and positive family history of cancer. Onkologie 2009, 32, 182-188. [CrossRef] [PubMed]

45. Tommiska, J.; Jansen, L.; Kilpivaara, O.; Edvardsen, H.; Kristensen, V.; Tamminen, A.; Aittomäki, K.; Blomqvist, C.; Børresen-Dale, A.-L.; Nevanlinna, H. ATM variants and cancer risk in breast cancer patients from Southern Finland. BMC Cancer 2006, 6, 209. [CrossRef]

46. Broeks, A.; Urbanus, J.H.; Floore, A.N.; Dahler, E.C.; Klijn, J.G.; Rutgers, E.J.; Devilee, P.; Russell, N.S.; van Leeuwen, F.E.; van't Veer, L.J. ATM-heterozygous germline mutations contribute to breast cancer-susceptibility. Am. J. Hum. Genet. 2000, 66, 494-500. [CrossRef] [PubMed]

47. Bernstein, J.L.; Haile, R.W.; Stovall, M.; Boice, J.D., Jr.; Shore, R.E.; Langholz, B.; Thomas, D.C.; Bernstein, L.; Lynch, C.F.; Olsen, J.H.; et al. Radiation exposure, the ATM Gene, and contralateral breast cancer in the women's environmental cancer and radiation epidemiology study. J. Natl. Cancer Inst. 2010, 102, 475-483. [CrossRef]

48. Vahteristo, P.; Bartkova, J.; Eerola, H.; Syrjäkoski, K.; Ojala, S.; Kilpivaara, O.; Tamminen, A.; Kononen, J.; Aittomäki, K.; Heikkilä, P.; et al. A CHEK2 genetic variant contributing to a substantial fraction of familial breast cancer. Am. J. Hum. Genet. 2002, 71, 432-438. [CrossRef] [PubMed]

49. Kuusisto, K.M.; Bebel, A.; Vihinen, M.; Schleutker, J.; Sallinen, S.L. Screening for BRCA1, BRCA2, CHEK2, PALB2, BRIP1, RAD50, and CDH1 mutations in high-risk Finnish BRCA1/2-founder mutation-negative breast and/or ovarian cancer individuals. Breast Cancer Res. 2011, 13, R20. [CrossRef] [PubMed]

50. Akdeniz, D.; Schmidt, M.K.; Seynaeve, C.M.; McCool, D.; Giardiello, D.; van den Broek, A.J.; Hauptmann, M.; Steyerberg, E.W.; Hooning, M.J. Risk factors for metachronous contralateral breast cancer: A systematic review and meta-analysis. Breast 2019, 44, 1-14. [CrossRef] [PubMed]

51. Caligo, M.A.; Agata, S.; Aceto, G.; Crucianelli, R.; Manoukian, S.; Peissel, B.; Scaini, M.C.; Sensi, E.; Veschi, S.; Cama, A.; et al. The CHEK2 c.1100delC mutation plays an irrelevant role in breast cancer predisposition in Italy. Hum. Mutat. 2004, $24,100-101$. [CrossRef]

52. Teoh, V.; Tasoulis, M.K.; Gui, G. Contralateral Prophylactic Mastectomy in Women with Unilateral Breast Cancer Who Are Genetic Carriers, Have a Strong Family History or Are just Young at Presentation. Cancers (Basel) 2020, 12, 140. [CrossRef]

53. Paluch-Shimon, S.; Cardoso, F.; Sessa, C.; Balmana, J.; Cardoso, M.J.; Gilbert, F.; Senkus, E.; ESMO Guidelines Committee. Prevention and screening in BRCA mutation carriers and other breast/ovarian hereditary cancer syndromes: ESMO Clinical Practice Guidelines for cancer prevention and screening. Ann. Oncol. 2016, 27, v103-v110. [CrossRef] [PubMed]

54. Cybulski, C.; Huzarski, T.; Byrski, T.; Gronwald, J.; Debniak, T.; Jakubowska, A.; Górski, B.; Wokołorczyk, D.; Masojć, B.; Narod, S.A.; et al. Estrogen receptor status in CHEK2-positive breast cancers: Implications for chemoprevention. Clin. Genet. 2009, 75, 72-78. [CrossRef]

55. Keeney, M.G.; Couch, F.J.; Visscher, D.W.; Lindor, N.M. Non-BRCA familial breast cancer: Review of reported pathology and molecular findings. Pathology 2017, 49, 363-370. [CrossRef]

56. Massink, M.P.; Kooi, I.E.; Martens, J.W.; Waisfisz, Q.; Meijers-Heijboer, H. Genomic profiling of CHEK2*1100delC-mutated breast carcinomas. BMC Cancer 2015, 15, 877. [CrossRef] [PubMed]

57. Domagala, P.; Wokolorczyk, D.; Cybulski, C.; Huzarski, T.; Lubinski, J.; Domagala, W. Different CHEK2 germline mutations are associated with distinct immunophenotypic molecular subtypes of breast cancer. Breast Cancer Res. Treat. 2012, 132, 937-945. [CrossRef] [PubMed]

58. Cybulski, C.; Kluźniak, W.; Huzarski, T.; Wokołorczyk, D.; Kashyap, A.; Jakubowska, A.; Szwiec, M.; Byrski, T.; Dębniak, T.; Górski, B.; et al. Clinical outcomes in women with breast cancer and a PALB2 mutation: A prospective cohort analysis. Lancet Oncol. 2015, 16, 638-644. [CrossRef]

59. Musolino, A.; Bella, M.A.; Bortesi, B.; Michiara, M.; Naldi, N.; Zanelli, P.; Capelletti, M.; Pezzuolo, D.; Camisa, R.; Savi, M.; et al. BRCA mutations, molecular markers, and clinical variables in early-onset breast cancer: A population-based study. Breast 2007, 16, 280-292. [CrossRef] [PubMed]

60. Couch, F.J.; Hart, S.N.; Sharma, P.; Toland, A.E.; Wang, X.; Miron, P.; Olson, J.E.; Godwin, A.K.; Pankratz, V.S.; Olswold, C.; et al. Inherited mutations in 17 breast cancer susceptibility genes among a large triple-negative breast cancer cohort unselected for family history of breast cancer. J. Clin. Oncol. 2015, 33, 304-311. [CrossRef]

61. Kleiblova, P.; Stolarova, L.; Krizova, K.; Lhota, F.; Hojny, J.; Zemankova, P.; Havranek, O.; Vocka, M.; Cerna, M.; Lhotova, K.; et al. Identification of deleterious germline CHEK2 mutations and their association with breast and ovarian cancer. Int. J. Cancer 2019, 145, 1782-1797. [CrossRef]

62. Kilpivaara, O.; Bartkova, J.; Eerola, H.; Syrjakoski, K.; Vahteristo, P.; Lukas, J.; Blomqvist, C.; Holli, K.; Heikkila, P.; Sauter, G.; et al. Correlation of CHEK2 protein expression and c.1100delC mutation status with tumor characteristics among unselected breast cancer patients. Int. J. Cancer 2005, 113, 575-580. [CrossRef] [PubMed] 
63. Huzarski, T.; Cybulski, C.; Domagała, W.; Gronwald, J.; Byrski, T.; Szwiec, M.; Woyke, S.; Narod, S.A.; Lubiński, J. Pathology of breast cancer in women with constitutional CHEK2 mutations. Breast Cancer Res. Treat. 2005, 90, 187-189. [CrossRef]

64. Liu, C.; Wang, Y.; Wang, Q.-S.; Wang, Y.J. The CHEK2 I157T variant and breast cancer susceptibility: A systematic review and meta-analysis. Asian Pac. J. Cancer Prev. 2012, 13, 1355-1360. [CrossRef]

65. Minicozzi, P.; Bella, F.; Toss, A.; Giacomin, A.; Fusco, M.; Zarcone, M.; Tumino, R.; Falcini, F.; Cesaraccio, R.; Candela, G.; et al. Relative and disease-free survival for breast cancer in relation to subtype: A population-based study. J. Cancer Res. Clin. Oncol. 2013, 139, 1569-1577. [CrossRef]

66. Toss, A.; Venturelli, M.; Peterle, C.; Piacentini, F.; Cascinu, S.; Cortesi, L. Molecular Biomarkers for Prediction of Targeted Therapy Response in Metastatic Breast Cancer: Trick or Treat? Int. J. Mol. Sci. 2017, 18, 85. [CrossRef] [PubMed]

67. Toss, A.; Cortesi, L. Molecular Mechanisms of PARP Inhibitors in BRCA-related Ovarian Cancer. J. Cancer Sci. Ther. $2013,5,11$.

68. Toss, A.; Piacentini, F.; Cortesi, L.; Artuso, L.; Bernardis, I.; Parenti, S.; Tenedini, E.; Ficarra, G.; Maiorana, A.; Iannone, A.; et al. Genomic alterations at the basis of treatment resistance in metastatic breast cancer: Clinical applications. Oncotarget 2018, 9, 31606-31619. [CrossRef] [PubMed] 